\title{
Quality management in educational organizations
}

\author{
Juhani Anttila, Academician, M.Sc. (Electrical Engineering) \\ International Academy for Quality \\ Aalto University, Department of Industrial Engineering and Management \\ Rypsikuja 4, FI-00660 Helsinki, Finland \\ E-mail: juhani.anttila@telecon.fi, www.QualityIntegration.biz \\ Kari Jussila, M.Sc. (Physical Electronics), M.Sc. (Economics) \\ Aalto University, Department of Industrial Engineering and Management \\ P.O. Box 15500, FI-00076 Aalto, Espoo, Finland \\ E-mail: kari.jussila@ aalto.fi
}

\begin{abstract}
Quality education is the main driver for the lifelong learning of people and the development of the organizations and society. Accordingly, also UNESCO's global vision for education towards 2030 is endeavoring to 'ensure inclusive and equitable quality education and promote lifelong learning opportunities for all'.

From the quality point of view, the existing situation is however very fragmented. A great variety of organizations provide formal and non-formal education for lifelong learning to people having very different needs and expectations, and the education providers and experts are not very aware of the general professional quality concepts and practices.

Very recently the international standardization committee ISO/PC 288 has started the work of harmonizing quality management in the educational organizations with the other organizations of the society by using the common professional approach. This new standardization will challenge all educational organizations, because it requires the adoption of the general basic quality concepts and quality management structures and practices. This will enable educational organizations to demonstrate their ability to provide consistently education to the requirements and strive for enhancing satisfaction of the involved parties.
\end{abstract}

\section{Introduction}

Education is in general considered as the main driver for the lifelong learning of people as human individuals, members of different organizations and citizens of the societies ${ }^{i}$. To ensure this, in the educational organizations quality should be considered as the essential factor in the education provision and learning. As the influential contributor, UNESCO in its new general global vision for education towards 2030 is endeavoring to 'ensure inclusive and equitable quality education and promote lifelong learning opportunities for all ${ }^{\text {'ii }}$.

A prominent role has been assigned to many kinds of formal and non-formal educational organizations for people's lifelong learning including:

- General education in kindergartens and pre-school, primary, elementary, middle schools, high schools, colleges and universities: Preparing for becoming and growing as a member of society and the citizenship, and contributing to the working life in the society and the world

- Training and education in vocational schools and training, tutoring or coaching centers: Preparing for an occupation and profession for the needs and 
expectations of the society and its organizations, and person's career development

- Training and education in adult education centers: Getting specialized knowledge and skills for citizenship and wellbeing

- Training and education by training organizations, education/training departments, consultants and other different types of non-formal educational service providers: Getting specialized knowledge and skills and networking

- Training and education by third sector organizations, for example sport clubs, youth centers, associations, etc.: Developing skills and attitudes

Distinction between the organizations exists in the funding source including public (subsidized), private (commercial), self-sufficient (internally generated revenue), and not-for-profit (sponsored). In addition to learning at formal and non-formal educational organization, a substantial part of the learning takes place informally and

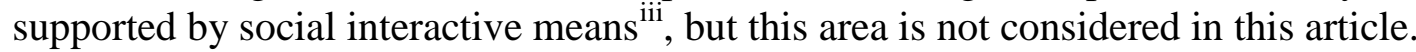
However, the organized education should also promote opportunities of the lifelong self-learning.

From the quality point of view, the general existing situation is very fragmented ${ }^{\mathrm{iv}}$. The education is provided by a great variety of educational organizations, and people in different societies have very different needs and expectations. Quality topic has largely been pointed up globally in educational discussions, and quality is said as crucial factor in education, although the used quality phraseology and approaches are not consistent. Quality of education has often proved to be only a lip service, and education professionals or experts seem not to be familiar with the common professional quality practices or methodology ${ }^{\mathrm{v}}$, which are well established in the most countries and millions of different organizations. Systematic quality approach is even perceived as unpleasant and frustrating, or as an additional and stressful issue. However, high quality does not take place accidentally but needs a professional approach and coherent quality realization in the processes of teaching and learning and within the educational organizations' management.

The international standardization committee ISO/PC $288^{\mathrm{vi}}$, 'Educational organizations management systems - Requirements with guidance for use', has started very recently the work of harmonizing quality management of the educational organizations with the other organizations of the society by using the common professional approach. The committee is creating at the first phase the standard ISO $21001^{\text {vii viii }}$, which is now at a working group internal (WD) draft stage. Experts from 39 countries are participating this work, and the final standard can be expected to be completed within a couple of years. This standard is based on the general requirement standard ISO 9001:2015 ${ }^{\text {ix }}$ that is applicable to all kind of organizations.

The standard ISO 21001 will challenge all educational organizations, because it requires the adoption of the general basic quality concepts and quality management structures and practices. The standard will enable educational organizations to demonstrate their ability to provide consistently education to learners conforming to be applicable with the legal and regulatory requirements and hence increasing the credibility of the organization, and aim at enhancing satisfaction of the interested parties of the educational organizations. This standard also advises educational organizations to develop their quality management that can promote to identify where the requirements are being met, where the gaps may exist, and the areas where improvement can be made. 


\section{The standard approach to quality management at educational organizations}

According to the standard ISO $21001^{\mathrm{x}}$, the educational organization should consider the quality management approach as a strategic decision and take into account influence of the learning environment, changes in the environment, and risks associated.

The professional starting point is the adoption of the general basic concepts and definitions and to set up the development on the general quality management principles (QMPs) that according to the standard ISO 9000:2015 ${ }^{\mathrm{xi}}$ consist of seven principles: (a) Customer focus, (b) Leadership, (c) Engagement of people, (d) Process approach, (e) Improvement, (f) Evidence-based decision making, and (g) Relationship management. These principles should be complemented and interpreted from the educational viewpoint that at present is under consideration in the committee ISO/PC 288.

The very basic terms that are necessary for the professional quality approach also in the educational organizations are quality and quality management, which are generally defined in the standard ISO 9000:2015.

ISO 21001 focuses on the interaction between the educational organization, teacher, learner and other interested parties. Interested party ${ }^{\mathrm{xii}}$ is a person or organization that can affect, be affected by, or perceive itself to be affected by the decision or activity of the educational organization. Learning results are co-created by the teacher and learner in certain environments through direct human interaction (that we have considered as the ontological system archetype model of all teaching/learning phenomena ${ }^{\text {xiii }}$ ) and indirectly through the teaching material and software based information technological means ${ }^{\text {xiv }}$.

Naturally, the learner's viewpoint has the essential role when we consider quality of education. The learner's satisfaction is defined as his/her perception of the degree to which the set of inherent characteristics of the achieved learning fulfills his/her needs and expectations. That is not, however, enough for the quality of learning, which requires satisfaction of all learning involved interested parties, for instance including that of the teachers ${ }^{\mathrm{xv}}$ (Figure 1).

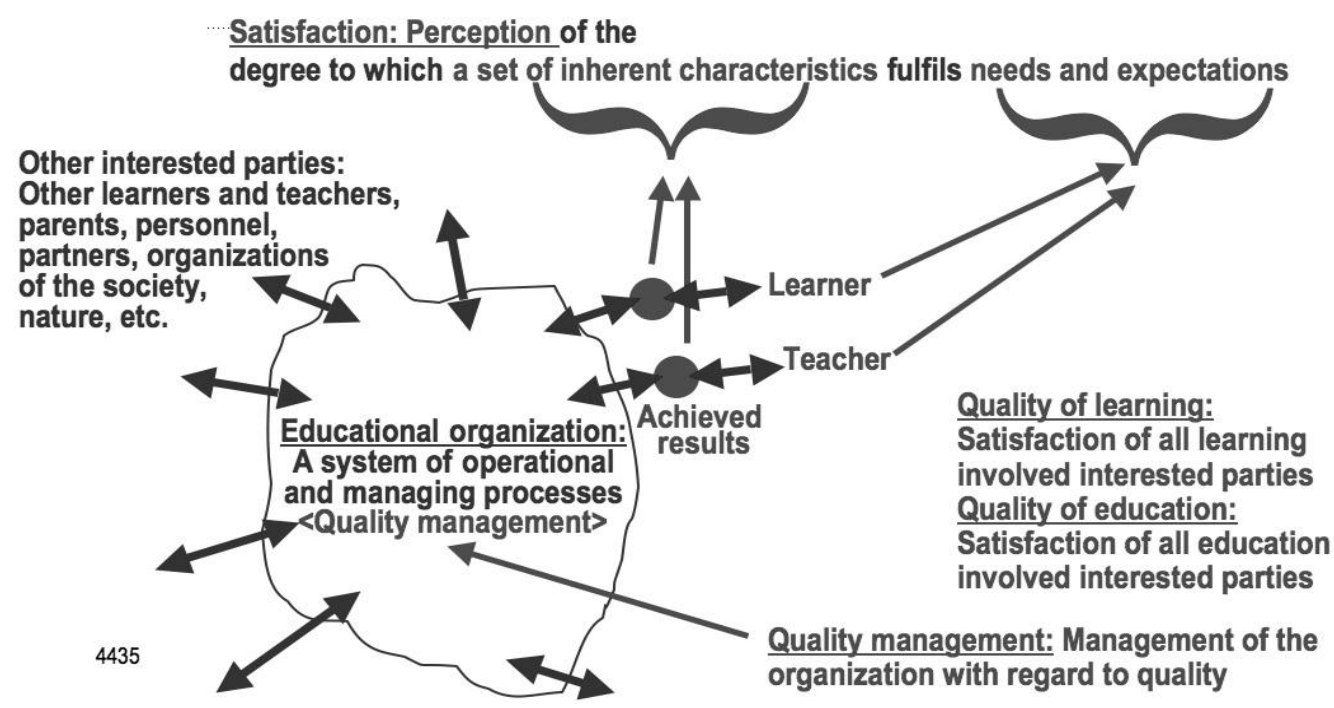

Figure 1. Quality and quality management in the context of an educational organization 
The essence of the quality of education is the satisfaction of all involved interested parties of the educational organization. The key challenge for quality is to recognize and fulfill the needs and expectations of the interested parties that may consist of involved individuals, organizations and the whole society and include learners, teachers, parents, government, non-governmental organizations (NGOs), trade unions, etc. Their needs and expectations cannot be standardized, nor even easily identified.

Learning needs are shifting ${ }^{\mathrm{xvi}}$ from 'learning to know and do' to 'learning to be and live together'. Tensions or dilemmas that become to be overcome in this context include the following dimensions ${ }^{\mathrm{xvii}}$ and are much dependent on culture:

- Global and local

- Universal and individual

- Tradition and modernity

- Long-term and short-term

- Consumption and sustainability

- Competition and equality

- Expansion of knowledge and human capacity to assimilate it

- Spiritual and material

Basic needs for human learning consist of literacy, oral expression, numeracy, problem solving, etc., and knowledge, skills, values, attitudes, etc. that the modern society factually demands. The broad scope of needs for societal learning include ethics and culture, science and technology, and economy.

Education is carried out through teaching processes and supporting processe ${ }^{\mathrm{xviii}}$ xix of the educational organization that is managed as a system. In the educational organizations quality is ensured through quality management that means the management of the organization with regard to quality. Hence, quality management is primarily aimed at the organization's own internal managerial purposes and seamlessly embedded within the organization's own internal operational and managerial processes. A part of the quality management is quality assurance, and its purpose is to create or strengthen confidence among the organization's external interested parties that the organization is capable to fulfill their requirements.

Quality improvement focuses on increasing the organization's ability to fulfill quality requirements. It is a key element of the professional quality management and is based on human and organizational learning.

Terminology, language and the text structure of the standard ISO 21001 are aligned with many other ISO management system standards (MSS), including quality management, environmental management, information security management, etc., through the application the ISO Directives Annex SL ${ }^{\mathrm{xx}}$ (Table 1). This helps organizations implement and integrate the requirements of different disciplines simultaneously, which is a relevant need also in the educational organizations. 
Table 1. Contents of the standard ISO 21001 according to the harmonized structure ${ }^{\mathrm{xxi}}$ and the chapters and clauses of the text, which present the quality management aspects required in the educational organizations and emphasize their integration within the normal organizational processes.
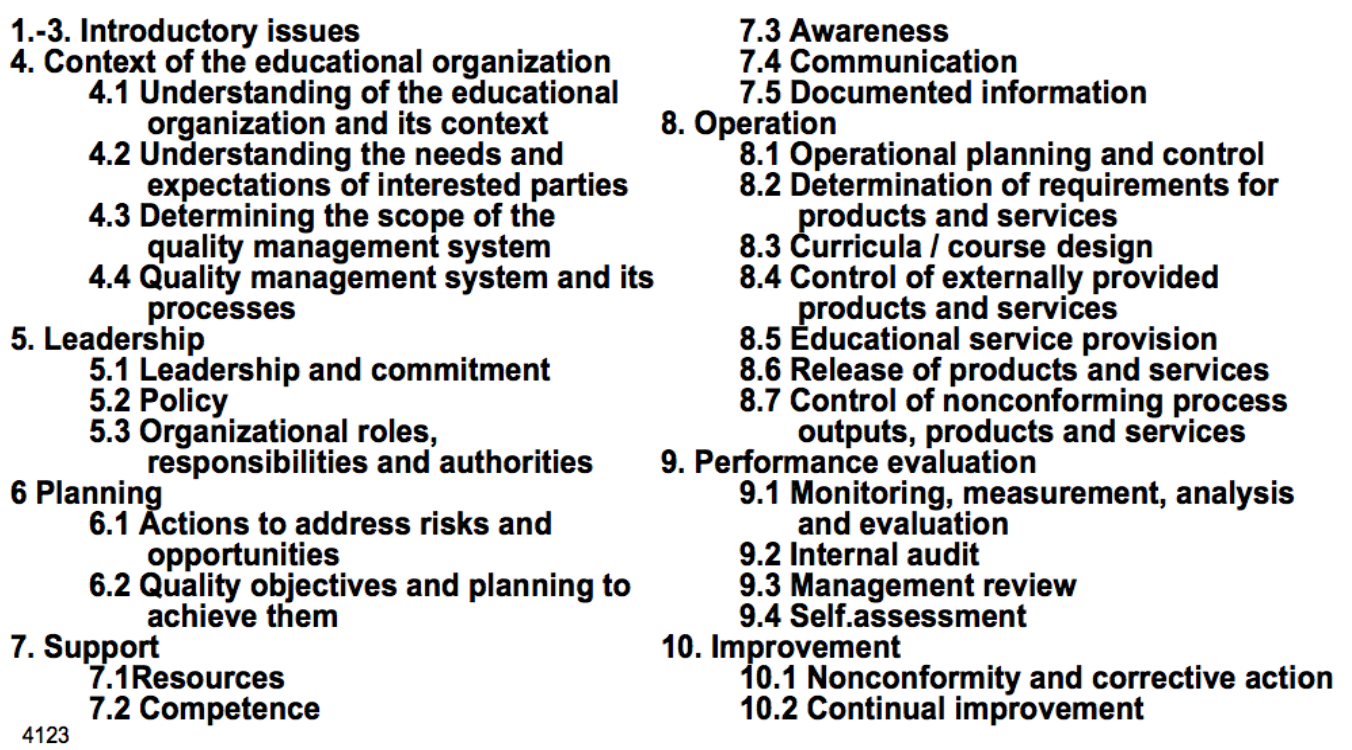

Risk management is the well-established practice of the quality discipline for preparing for uncertainties in the organizational activities. In the educational organizations, risk management is quite a new issue, but the new standard ISO 21001 will bring it also to them as a requirement. General guidance for the risk-based thinking and organizational practices is presented in the standard ISO $31000^{\text {xxii }}$.

Educational organizations need to meet requirements related to the privacy, information security and intellectual property issues. Several standards are available for managing these specific issues ${ }^{\text {xxiir }}$.

Educational organizations must provide learning opportunities that meet individual accessibility requirements. However, many organizations are experiencing reduced funding and shortages of resources. As well, there are inequities within systems that influence on the development and delivery of educational services.

\section{Implementing the standard requirements}

All requirements of ISO 21001 are generic and intended to be applicable to all educational organizations that provide, share and facilitate the construction of knowledge to learners through teaching, training or research, regardless of the type, size and education service provided. Hence, the application area of the standard is very broad.

All organizations, including educational organizations, always have some level of quality and quality management naturally integrated with the organization's normal operational and managerial processes. Hence, it is not necessary to build any particular 'quality management system'. The most essential issue is to improve the existing situation, and in fact it can be done continually. This can also be understood as the implicit purpose of the standard ISO 21001.

All general standardization strives for positive and proactive aims ${ }^{\text {xxiv }}$, including (a) improved organizational performance and confidence, and quality of products, (b) decreased operational costs, and (c) improved communication between people and 
organizations. However, at the same time it also has general cons including inadequacies, inconsistencies and other problems mainly due to the normal standardization processes and particularly the consensus practices.

According to the ISO definition ${ }^{\mathrm{xxv}}$, standardization is "an activity giving solutions for repetitive application, to problems essentially in the spheres of science, technology and economics, aimed at the achievement of the optimum degree of order in a given context. Generally, the standardization activity consists of the processes of formulating, issuing and implementing standards". This means that the implementation of standards in organizations is a part of the standardization. Hence, it also is the responsibility of the educational organizations' management and experts to take advantage of science, technology and experience in applying the standards and clarify, correct, and complete general standards and find creative solutions in their implementations in order to achieve their own organizational benefits ${ }^{\mathrm{xxvi}}$.

Implementation of quality management based on the standard ISO 21001 and with the stimulation of excellence and innovation ${ }^{\mathrm{xxvii}}$ can be considered as the challenge to the educational organizations.

The quality management system for educational organizations (QMSEO) is one of the most central terms in the ISO 21001 standard. It is however a problematic concept. There are no specific standards that address the QMSEO as such holistically, and hence the content of the QMSEO always depends only on the particular educational organization's and involved persons' opinion. ISO 21001 does not define the QMSEO as a whole; it only presents requirements for it. It is impossible to know where the border exists between the general management of the organizational system and the QMSEO. According to its definition, the QMSEO is seamlessly embedded within the management of the educational organization. Hence, the whole concept QMSEO is useless in practice. It may be replaced by the expression 'management of the educational organization with regard to quality in a systemic way'.

Process approach is the most central issue in realizing the organization's quality management ${ }^{\mathrm{xx} v i i i}$. This is, however, a demanding challenge, because the organizational system consists of complex organizational structures and processes of relating $^{\mathrm{xxix}}$. Process management should have a holistic approach and especially the focus on people aspects. A critical issue for process performance and process management is the behavior of individual human performers ${ }^{\mathrm{xxx}}$, both employees and managers, and how they understand the overall aims and their roles in the process scope within the larger organizational context they are involved in. The important topic of process management is, however, considered in the standard ISO 21001 only in a sketchy way.

\section{Performance evaluation}

The standard ISO 21001 considers the performance measurements and evaluation from many different viewpoints including:

- Monitoring, measurement, analysis and evaluation

- Internal audit

- Management review

- Self-assessment

without going deeper in the evaluation methodologies. We have comprehensively considered the topic in another article ${ }^{\mathrm{xxxi}}$. The most important issue is that the performance evaluations lead to the performance improvement and create confidence among the interested parties of the educational organizations. 
Evaluating the performance of quality management is a problematic issue. Quality management aims at results or outputs of organizational activities or processes to fulfill needs and expectations of all interested parties and through that ensure the sustained success of an organization. Quality management is an essential part of the management of an organization. All its activities are seamlessly embedded with the organizational system and processes and their management. Quality management covers the whole area of the management of an organization from the top management to management of operational activities (business processes) and individual self-management of employees. It is impossible say where the border between business management and quality is. Hence, instead of quality management evaluations one can carry out comprehensive evaluations of the performance of the business processes and results. If needed there are analytical methods to find out the effect of the individual quality management practices on the overall performance of the business processes or the whole organizational system ${ }^{\text {xxxii }}$.

\section{Conclusion}

The standard ISO 21001 has seen as an unprecedented point in history ${ }^{\text {xxxii }}$ when the educational organizations have many opportunities to collaborate, share and innovate with each other and also with the experts of the quality discipline. Consortiums of educational organizations work closely together to coordinate the development/delivery of resources, to identify and support improvements to educational practices, theory, and to foster and encourage innovation and creativity. Through digital technologies, learners have access to a wealth of resources including the new and emerging technologies that can be used by learners to create content and to connect with each other.

\section{References}

i Anttila, J. and Jussila, K. (2015). Striving for the 'Quality society' through high quality education and lifelong learning, $59^{\text {th }}$ EOQ Congress, Athens, Greece.

${ }^{\text {ii } U N E S C O ~(2015) . ~ I n c h e o n ~ D e c l a r a t i o n, ~ E d u c a t i o n ~ 2030: ~ T o w a r d s ~ i n c l u s i v e ~ a n d ~}$ equitable quality education and lifelong learning for all. https://en.unesco.org/worldeducation-forum-2015/incheon-declaration

iii Cross, J. (2003). Informal learning - the other $80 \%$. http://www.americalearningmedia.net/edicion-000/3-analysis/3231-informal-learningthe-other-80

iv Anttila, J, and Jussila, K. (2015). Quality evaluation of education and learning. World Quality Forum, Budapest.

${ }^{\mathrm{v}}$ UNESCO (2015). Education for all 2000 - 2015: Achievements and challenges. EFA Global monitoring report. UNESCO Publishing, Paris, France.

${ }^{v i}$ ISO (2015). ISO/PC 288 Educational organizations management systems Requirements with guidance for use. http://www.iso.org/iso/home/standards_development/list_of_iso_technical_committee s/iso_technical_committee.htm?commid=4960304

vii ISO (2014). ISO/NP 21001 Educational organization management systems -Requirements with guidance for use. http://www.iso.org/iso/home/store/catalogue_tc/catalogue_detail.htm?csnumber $=662$ $\underline{66}$ 


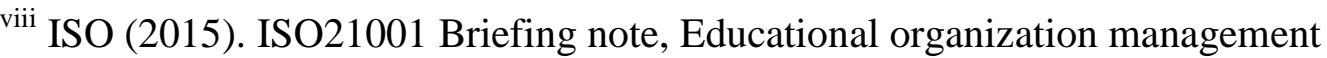
systems. http://www.iso.org/iso/iso21001_briefing_note.pdf

${ }^{\text {ix }}$ ISO (2015). ISO 9001:2015 Quality management systems - Requirements, ISO, Geneva, Switzerland.

${ }^{x}$ ISO (2015). ISO 21001(WD) Educational organization management systems -Requirements with guidance for use.

${ }^{\mathrm{xi}}$ ISO (2015). ISO 9000:2015 Quality management systems - Fundamentals and vocabulary. ISO, Geneva, Switzerland.

xii Ibid.

xiii Anttila, J. and Jussila, K. (2015). Striving for the 'Quality society' through high quality education and lifelong learning, $59^{\text {th }}$ EOQ Congress, Athens, Greece.

xiv Ibid.

${ }^{\mathrm{xv}}$ ISO (2015). ISO 9000:2015 Quality management systems - Fundamentals and vocabulary. ISO, Geneva, Switzerland.

${ }^{x v i}$ Delors, J. (1998). Learning: The treasure within. UNESCO Paris, France. http://unesdoc.unesco.org/images/0010/001095/109590eo.pdf xvii Ibid.

xviii Anttila, J. and Jussila, K. (2015). Striving for the 'Quality society' through high quality education and lifelong learning, $59^{\text {th }}$ EOQ Congress, Athens, Greece.

${ }^{x i x}$ Anttila, J. and Jussila, K. (2013). An advanced insight into managing business processes in practice, Total Quality Management \& Business Excellence, Volume 24, Issue 7-8.

${ }^{x x}$ ISO/IEC (2012). Directives, Part 1, Consolidated ISO Supplement - Procedures specific to ISO, Annex SL, Proposals for management system standards, ISO, Geneva, Switzerland

xxi Ibid.

${ }^{x x i i}$ ISO (2009). ISO 31000 Risk management - Principles and guidelines, ISO, Geneva, Switzerland.

xxiii ISO/IEC (2015). ISO/IEC JTC 1/SC 27 - IT Security techniques.

http://www.iso.org/iso/iso_catalogue/catalogue_tc/catalogue_tc_browse.htm?commid $=45306$

Anttila, J. and Jussila, K. (2015). ISO 9001:2015 - A questionable reform. What should the implementing organizations understand and do? World Quality Forum, Budapest.

${ }^{\mathrm{xxv}}$ ISO/IEC (2004). ISO Guide 2, Standardization and related activities - General vocabulary, ISO, Geneva, Switzerland.

${ }^{x x v i}$ Anttila, J. and Jussila, K. (2015). ISO 9001:2015 - A questionable reform. What should the implementing organizations understand and do? World Quality Forum, Budapest.

${ }^{x x v i i}$ ISO, 2015. ISO21001 Briefing note, Educational organization management systems, http://www.iso.org/iso/iso21001_briefing_note.pdf

${ }^{x x v i i i}$ Anttila, J. and Jussila, K. (2013). An advanced insight into managing business processes in practice, Total Quality Management \& Business Excellence, Volume 24, Issue 7-8.

${ }^{x x i x}$ Stacey, R. (2002). Organizations as complex responsive processes of relating. Journal of Innovative Management Vol. 8, No. 2, Salem USA, Winter 2002/2003. ${ }^{x x x}$ Anttila, J. and Jussila, K. (2013). People aspects, an undervalued area in the procedures of business process management, EOQ Congress in Tallinn Estonia 
${ }^{x x x i}$ Anttila, J, and Jussila, K. (2015). Quality evaluation of education and learning. World Quality Forum, Budapest.

xxxii Holopainen, S. Lillrank, P. and Paavola, T. (2001), Linking IT to business, Studentlitteratur, Stockholm, Sweden

xxxiii ISO (2015). ISO 21001(WD) Educational organization management systems -Requirements with guidance for use. 